\title{
Kaizen a Tool for Continuous Quality Improvement in Indian Manufacturing Organization
}

\author{
Ravinder Kumar \\ Department of Mechanical Engineering \\ Amity University, Noida-201303, India \\ E-mail-rkumar19@amity.edu
}

(Received October 12, 2018; Accepted January 21, 2019)

\begin{abstract}
Kaizen is a practice of continuous improvements in manufacturing, assembly, quality and engineering. In this paper author have discussed the problems faced by a leading automobile manufacturing organization on quality of interior parts of the automobile like plastics and rubber. During study author used a new technique called "Global Customer Audit" which is basically a vehicle audit from final customer point of view for interior parts of automobiles. During this audit, author has observed various defects and by using different quality control tools like pareto charts, histograms, check sheets and arranged defects according to their intensity or magnitude of occurrence i.e. finding useful one from trivial many. In this paper, the author found the root cause of defects by using different quality control tools. Kaizen is done to remove these defects and continuously improve products and production processes. Kaizen helps in making manufacturing process leaner, simple and fitter. The main purpose of this paper is to discuss the concept of Kaizen, its application in case organization for solving problems raising big quality concerns on a day to day bases.
\end{abstract}

Keywords- Global customer audit, Kaizen, Process improvement, Quality control tools.

\section{Introduction}

The word Kaizen is a Japanese word, which means continuous improvement. It stresses on improvement, which is done to improve process parameters. It is a tool, which is used to end another Japanese policy 3M- MUDA, MURA, and MURI meaning inconvenience, inconsistency and wastage respectively. Kaizen laid emphasis on continuous improvements as compared to onetime improvement, which is nothing but innovation. It is classified as - productivity, quality, cost cutting, delivery, safety and morale. There are four basic steps, which help in the better implementation of Kaizen. These steps are PDCA - Plan, Do, Check and Act.

In today's competitive and fast growing world, only efficient managed organizations can survive. With the development, implementation and management of new technologies are also important. Japanese professionals always focus on implementation with the development of technologies. It gives an edge to them in industrial developments. Prashar (2014) studied the case of the steering manufacturing organization. The organization was facing different issues of falling customer demand, increasing the cost of production. By using Kaizen tools like VSM, the organization was able to find the root cause of the issues. By improving the assembly line using lean process techniques, the case organization was able to reduce its inventory by sixty-six percent, defect rate reduced by thirty-two percent and effectively managed equipment, manpower and storage space. Chung (2018) developed the concept of Kaizen wheel, combining the six types of tools of Kaizen. This philosophy helps in designing and implementation of Kaizen programs. 
International Journal of Mathematical, Engineering and Management Sciences

Vol. 4, No. 2, 452-459, 2019

https://dx.doi.org/10.33889/IJMEMS.2019.4.2-037

Berger (1997) studied the Kaizen for standardization of process, product and design of works. Singh and Singh (2018) studied the performance of different elements of Kaizen in an Indian manufacturing organization. Authors identified the important elements of Kaizen and studied their effects on the performance of the organization after implementation. Authors conducted a questionnaire-based survey in case organization for study. Macpherson et al. (2015) studied the sustainable methods of Kaizen and stressed on channelizing the creativity of workers and creating the driving energy behind innovation in the workplaces.

Arya and Choudhary (2015) studied Kaizen implementation in Indian SMEs. Problems of low production, poor quality and higher lead-time can be resolved by Kaizen application. Final results have shown saving in money and time. Oropesa Vento et al. (2016) studied the effect of Kaizen implementation on managerial commitment and human resource development. Arya and Jain, (2014) studied the benefits of Kaizen in small scale Industries in India. Implementation of Kaizen has reduced processing time and working area management improved. Ma et al. (2017) studied that enablers of personnel are first on priority, enablers of software are second and hardware factors are third on priority. Authors concluded that Kaizen is the most preferred improvement method. Kumar et al. (2018) studied the opportunities of continuous improvement in Indian SMEs by using value stream mapping (VSM). Papic et al. (2017) studied factors critical for Lean Six Sigma implementation success.

Authors observed that lean-Kaizen provides a better chance of continuous improvement in productivity and quality of products. Authors further observed that knowledge of lean tools, technique and willingness to identify and eliminates waste are very less in workers of Indian SMEs.

In this world of competition and updating technologies, the auto sector is facing tough competition in India. Case organization, is the largest seller of four-wheelers in India. Kaizen can be done easily by any company in any field. The only requirement is to make a continuous improvement, which can be done with minimal investment. Section 2 discusses the motivation toward continuous quality improvement (Kaizen). Section 3 discusses two cases of Kaizen. Finally the conclusion is given in Section 4.

\section{Motivations Toward Continuous Quality Improvement (Kaizen)}

Globalization has leveled the field of competition, especially with the development in communication techniques, development in one part of globe based on technology, quality and cost have a global impact. Organizations in every part of the globe are focusing on modern quality control techniques. Management techniques like PDCA, Quality circle, cross-functional teams, total productive maintenance have become more relevant. Continuous quality improvement (Kaizen) is a way out in cut throat competition. Kaizen needs continuous efforts in improving techniques and process and at the most motivation.

There are few motivating factors for Kaizen implementation:

- Top management policy and commitment (Kaizen,1986)

- Effective and flexible suggestion system (Womach et al.,1990; Shah and Naik, 2018)

- The existence of problem solving techniques (Gracia-Sabter and Marin-Garciaet, 2011; Khanna et al., 2017a; Khanna et al., 2017b; Amrutkar and Kamalja, 2017)

- Supportive organization structure (Magnier-Watanabe, 2011). 
International Journal of Mathematical, Engineering and Management Sciences

Vol. 4, No. 2, 452-459, 2019

https://dx.doi.org/10.33889/IJMEMS.2019.4.2-037

\section{Study of Kaizen Cases}

Author has studied two cases under this section.

\subsection{Introduction of Case Organization}

Case organization is the largest automobile manufacturer in India with a total production of 18 lakhs vehicle in 2017. It produces 6500 vehicles per day in Gurgaon plant only. Secrete behind success of case organization is its philosophy and adoption of Japanese techniques like Kaizen, 5S (Seiri, Seiton, Seiso, Seiketsu, Shitsuke meaning Sort, Set in order, Shine, Standardize, Selfdiscipline respectively), 3M (MUDA, MURA, and MURI meaning inconvenience, inconsistency and wastage respectively), 3G (Genchi, Genbutsu and Genjitsu meaning go to actual place, see the actual thing and take necessary action respectively) etc. The case study has been done in Quality Assurance Parts Quality (QAPQ) department dealing with interior plastic parts developed by different vendors or suppliers for running models as well as new models. Philosophy of quality assurance guide the vendors to make improvements in their manufacturing processes, analyze and initiate countermeasures for processes related defects during trials and finally inspection of products.

Case organization follows a technique called global customer audit (GCA). This is basically used to find defects in products, keeping customer point of view. This whole process is independent of quality checks done in the production department. Its follow a three cycle process - vehicle preparation and shower test, dynamic test and drive cycle and static appearance check. By doing GCA monitoring, data is collected about various defects, which are coming in running models.

\subsection{Kaizen Case 1}

It is observed that case organization was following different quality control processes still there were some problems repeatedly coming in the picture during GCA monitoring such as:

- Flashes (cutting not good)

- Sink Marks, line marks etc. (defects arising due to injection molding processes)

- Gap found in between parts (fitment not good)

- Paint not good (color difference)

- Short moulding

- Dust on ORVM's (Outside Rear View Mirror) and door handles.

For collecting, analyzing data and identifying root causes, different tools are used such as Pareto chart, histograms, cause and effect diagrams, control charts, scatter diagrams, graphs or flow charts and check sheets. Finally, Kaizen is used to remove these defects.

Below is Pareto chart for some defects observed during monitoring for different plants and models (as shown in Figure 1). 
International Journal of Mathematical, Engineering and Management Sciences

Vol. 4, No. 2, 452-459, 2019

https://dx.doi.org/10.33889/IJMEMS.2019.4.2-037

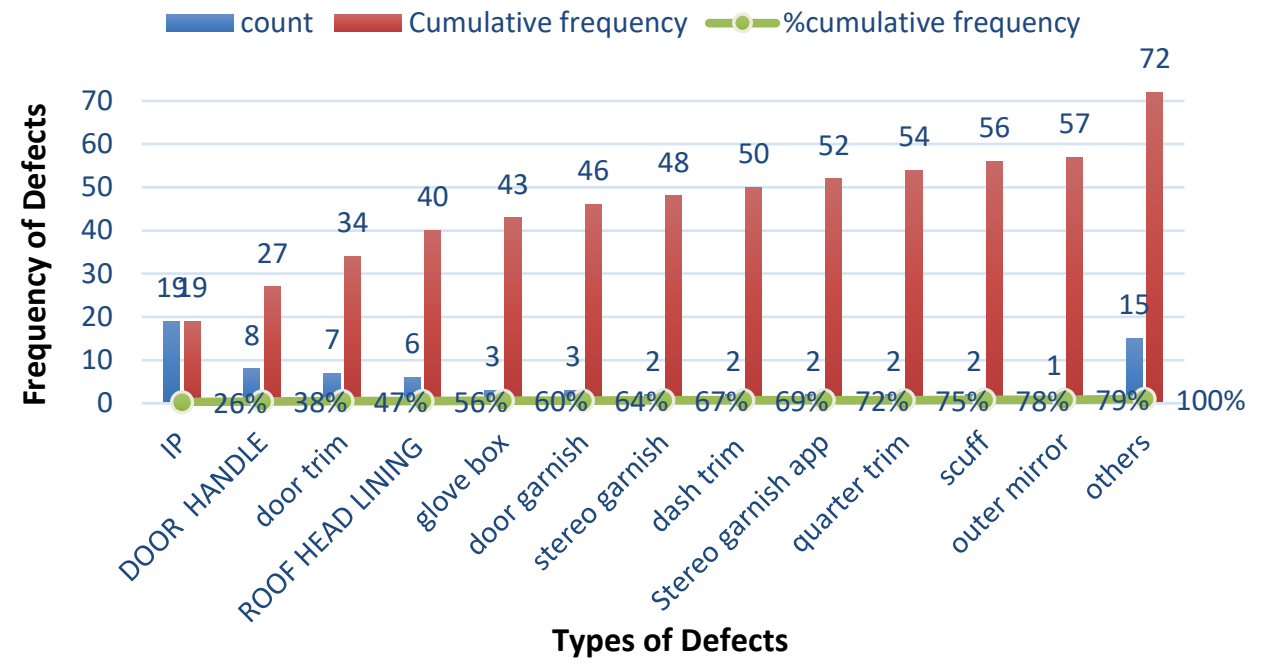

Figure 1. Frequency of defects observed

For the solution to this problem, the author used tools such as $3 \mathrm{G}-\mathrm{Genchi}$, Genbutsu and Genjitsu meaning go to an actual place, see the actual thing and take necessary action respectively. Therefore, the author visited Vendor Company, which makes these ORVMs. On vendor's plant author identified following possible root causes for occurrence and outflow of these defects:

\section{Possible Causes for Dust/Dirt under Paint:}

- Use of low quality paint

- Flying dust in booth air

- Dust not cleaned from the surface of the object

- Spray nozzle chocked/ not cleaned

- Fixtures/ hangers not cleaned

- Suction filter not changed before painting

- Turn table of the robot not cleaned

\section{Observation on Said Problems:}

- Dust was sticking on turn table due to positive draft in base coat area and then feeding to the clear coat, the tacky sheet must be made available on the turn table and fumes collected must be gauged and tacky sheet must be replaced on set frequency (as fumes collected will certainly stick on the part).

- In the entrance of paint shop tacky sheet stand must be there and replacement of sheet on set frequency should be done. (Even though the painting is done in closed enclosure still atmospheric dust enters through the carriers in the vicinity)

- Actions for every painting defect must be analyzed and action taken must be monitored on a regular basis 
International Journal of Mathematical, Engineering and Management Sciences

Vol. 4, No. 2, 452-459, 2019

https://dx.doi.org/10.33889/IJMEMS.2019.4.2-037

\section{The reason of Non-Detection of Defects during Normal Quality Inspection:}

- The author observed that the dust in parts was not detected by the inspector in predispatch inspection (PDI) and final inspection.

- Poison cake test (checking if the part is getting detected by the inspector then making the skill matrix accordingly) deputing the inspectors based on skill level. (This is missing afore mentioned observation makes it evident).

\section{Kaizen Suggested and Implemented:}

- Coating area covered by adhesive film pasted on the wall, so that paint fumes, dust and line are catched by the film.

- Regular cleaning of arms, jigs and fixtures by tag-rag cloth before loading was suggested.

- A regular sprinkle of water on the mat in an interval of every 2 hours was recommended to avoid sticking of environmental dust on the part.

- Inspector/operator skill competency to be reviewed as per defect acceptance level.

\subsection{Kaizen Case 2}

The author observed another issue of stains and weather patch on roof lining of the automobile. Regular inspection techniques were not able to identify which material or compound or liquid is causing these stains (shown in Figure 2). It was may be due to water, Colin used for cleaning or any other substance which is used in making roof lining such as adhesive etc. (Table 1). The author also observed that finish of roof lining on edges was not proper even though cutting done with hydraulic press. To solve this problem author followed Plan Do Check and Act (PDCA) technique. After doing PDCA, the author suggested setting up of UV rays detection set up under Kaizen (Figure 3).

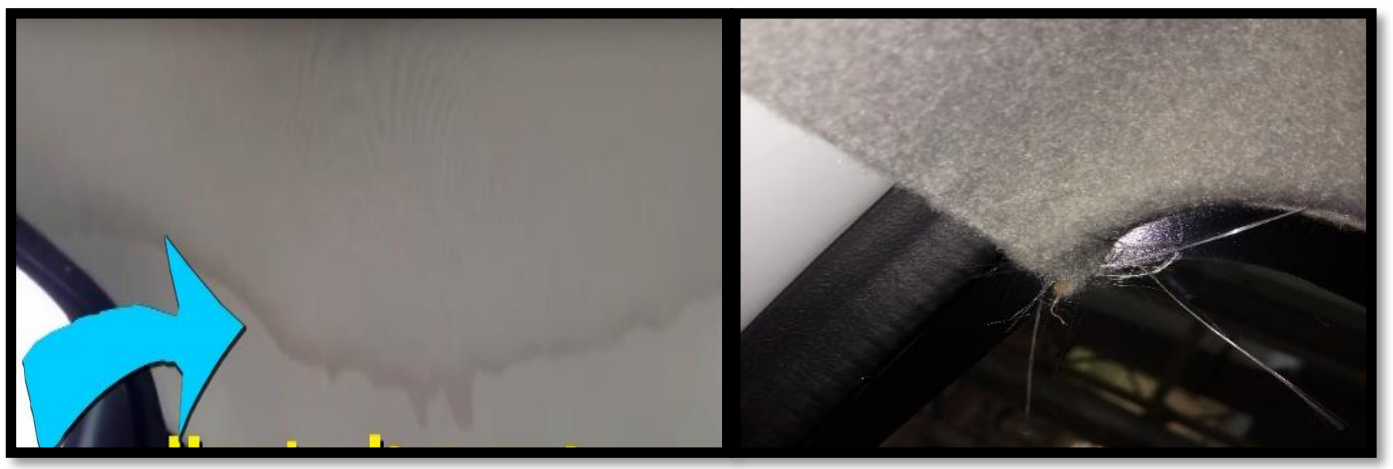

Figure 2. Defects selected for Kaizen-2 (stain marks on roof and poor cutting of mats)

Table1. Five test samples to check stains

\begin{tabular}{|c|c|c|c|c|c|}
\hline \multirow{2}{*}{ Front \& rear side both } & Sample 1 & Sample 2 & Sample 3 & Sample 4 & Sample 5 \\
\cline { 2 - 6 } & Water & Colin cleaner & AB24 adhesive & Felt adhesive & AB29 adhesive \\
\hline
\end{tabular}


International Journal of Mathematical, Engineering and Management Sciences

Vol. 4, No. 2, 452-459, 2019

https://dx.doi.org/10.33889/IJMEMS.2019.4.2-037

After five samples were made to check stains, following observations were made:

- Action for outflow was taken and $100 \%$ inspection started.

- 5 test samples were prepared of roof lining and put for the $72 \mathrm{hrs}$ ageing cycle as per drawing. These samples were prepared (by using adhesives commonly used in industry for making roof lining) to check which chemical is causing staining on roof lining.

In this simple but innovative way, we found the actual case and we did improvements regarding that substance.

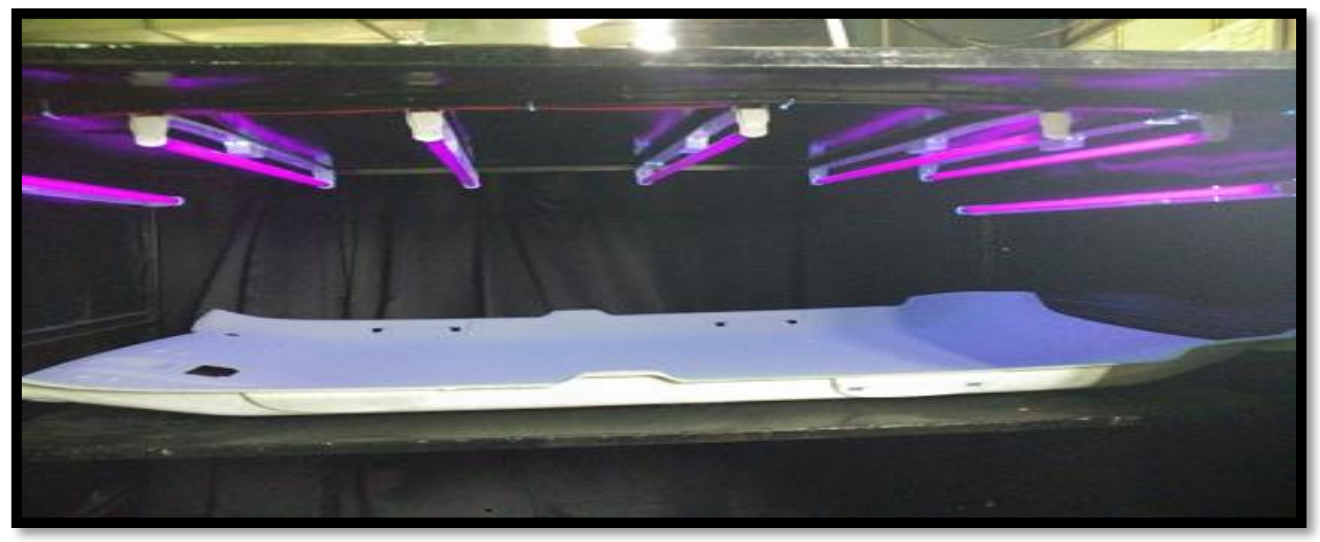

Figure 3. UV rays detection set up under Kaizen

\section{Other Kaizen suggested and preformed were:}

- The fixture used for pre-dispatch inspection modified (tolerance making colour coding Green in Red).

- Checking method Go-no-Go gauge to be used rather than taper scale so that there was no chance of any error in measuring and use of ball gauge to measure equally in all directions. This use of Go-no-Go gauze also saves a lot of time which is beneficial of mass production.

- Fixture block visibility was improved by cutting window made of acrylic sheet block.

\section{Conclusion}

Kaizen is a Japanese word, which implies any change for good. It implies that continuously done small changes help in improving manufacturing techniques and processes. There are many tools which help in Kaizen such as 5S, 3G, 3M etc. PDCA is an important cycle for doing Kaizen. Various quality control tools can also be used to implement Kaizen effectively and in a planned way. In case of organization author have worked on the different small problem using Kaizen and found the solution of them. In daily routine inspection these problems were not detected and 
International Journal of Mathematical, Engineering and Management Sciences

Vol. 4, No. 2, 452-459, 2019

https://dx.doi.org/10.33889/IJMEMS.2019.4.2-037

observed. By using "Global Customer Audit" with the help of a separate team, author detected and suggested a permanent solution of these problems. The full process has been done under two cases (Case no.1 and Case no.2). Kaizen played a very important role in solving these problems. Finding of this study can motivate other industries in making their process world class by removing the small problem through continuous improvements and make them part of daily routine.

\section{Conflict of Interest}

The author confirms that this article contents have no conflict of interest.

\section{Acknowledgement}

The author would like to express his sincere thanks to the reviewers and Editor for their valuable suggestions towards the improvement of the paper.

\section{References}

Amrutkar, K. P., \& Kamalja, K. K. (2017). An overview of various importance measures of reliability system. International Journal of Mathematical, Engineering and Management Sciences, 2(3), 150-171.

Arya, A. K., \& Choudhary, S. (2015). Assessing the application of Kaizen principles in Indian small-scale industry. International Journal of Lean Six Sigma, 6(4), 369-396.

Arya, A. K., \& Jain, S. K. (2014). Impacts of Kaizen in a small-scale industry of India: a case study. International Journal of Lean Six Sigma, 5(1), 22-44.

Berger, A. (1997). Continuous improvement and Kaizen: standardization and organizational designs. Integrated Manufacturing Systems, 8(2), 110-117.

Chung, C. H. (2018). The Kaizen wheel-an integrated philosophical foundation for total continuous improvement. The TQM Journal, 30(4), 409-424.

Garcia-Sabater, J. J., \& Marin-Garcia, J. A. (2011). Can we still talk about continuous improvement? rethinking enablers and inhibitors for successful implementation. International Journal of Technology Management, 55(1/2), 28-42.

Kaizen, I. M. (1986). The key to Japan's competitive success. MacGraw-Hill, New York.

Khanna, A., Gautam, P., \& Jaggi, C. K. (2017a). Inventory modeling for deteriorating imperfect quality items with selling price dependent demand and shortage backordering under credit financing. International Journal of Mathematical, Engineering and Management Sciences, 2(2), 110-124.

Khanna, A., Kishore, A., \& Jaggi, C. K. (2017b). Inventory modeling for imperfect production process with inspection errors, sales return, and imperfect rework process. International Journal of Mathematical, Engineering and Management Sciences, 2(4), 242-258.

Kumar, S., Dhingra, A., \& Singh, B. (2018). Lean-Kaizen implementation: a roadmap for identifying continuous improvement opportunities in Indian small and medium sized enterprise. Journal of Engineering, Design and Technology, 16(1), 143-160.

Ma, J., Lin, Z., \& Lau, C. K. (2017). Prioritising the enablers for the successful implementation of Kaizen in China: a fuzzy AHP study. International Journal of Quality \& Reliability Management, 34(4), 549568. 
International Journal of Mathematical, Engineering and Management Sciences

Vol. 4, No. 2, 452-459, 2019

https://dx.doi.org/10.33889/IJMEMS.2019.4.2-037

Macpherson, W. G., Lockhart, J. C., Kavan, H., \& Iaquinto, A. L. (2015). Kaizen: a Japanese philosophy and system for business excellence. Journal of Business Strategy, 36(5), 3-9.

Magnier-Watanabe, R. (2011). Getting ready for Kaizen: organizational and knowledge management enablers. Vine, 41(4), 428-448.

Oropesa Vento, M., Garcia Alcaraz, J. L., Maldonado Macias, A. A., \& Martinez Loya, V. (2016). The impact of managerial commitment and Kaizen benefits on companies. Journal of Manufacturing Technology Management, 27(5), 692-712.

Papic, L., Mladjenovic, M., Carrión García, A., \& Aggrawal, D. (2017). Significant factors of the successful lean six-sigma implementation. International Journal of Mathematical, Engineering and Management Sciences, 2(2), 85-109.

Prashar, A. (2014). Redesigning an assembly line through Lean-Kaizen: an Indian case. The TQM Journal, 26(5), 475-498.

Shah, N. H., \& Naik, M. K. (2018). Inventory policies for price-sensitive stock-dependent demand and quantity discounts. International Journal of Mathematical, Engineering and Management Sciences, 3(3), 245-257.

Singh, J., \& Singh, H. (2018). Enigma of KAIZEN approach in manufacturing industry of Northern India-a case study. International Journal of Quality \& Reliability Management, 35(1), 187-207.

Womack, J. P., Womack, J. P., Jones, D. T., \& Roos, D. (1990). Machine that changed the world. Simon and Schuster Inc., New York.

(c) (i) Original content of this work is copyright (C) International Journal of Mathematical, Engineering and Management Sciences. All rights reserved. Except of uses under a Creative Commons Attribution 4.0 International (CC BY 4.0) license at https://creativecommons.org/licenses/by/4.0/ 